\title{
A rare case of pharyngeal perforation and expectoration of an entire anterior cervical fixation construct
}

\author{
Syed A. Quadri, MBBS, John Capua, DO, Vivek Ramakrishnan, DO, Raed Sweiss, DO, \\ Marc Cabanne, DO, Jerry Noel, DO, Brian Fiani, DO, and Javed Siddiqi, MD, PhD \\ Institute of Clinical Orthopedic and Neurosciences, Desert Regional Medical Center, Palm Springs, California
}

\begin{abstract}
Anterior cervical discectomy and fusion (ACDF) is a very common surgery performed globally. Although a few cases of expectorating screws or extrusion of screws into the gastrointestinal tract through esophageal perforations have previously been reported, there has not been a case reporting pharyngeal perforation and entire cervical construct extrusion in the literature to date. In this report the authors present the first case involving the extrusion of an entire cervical construct via a tear in the posterior pharyngeal wall. An 81-year-old woman presented to the emergency department (ED) with a complaint of significant cervical pain 5 days after a fall due to a syncopal event. Radiological findings showed severe anterior subluxation of C-2 on C-3 with no spinal cord signal change noted. She underwent ACDF at the C2-3 level utilizing a polyetheretherketone (PEEK) cage, allograft, autograft, and a nontranslational plate with a locking apparatus and expanding screws. The screw placement was satisfactory on postoperative radiography and the Grade II spondylolisthesis of C-2 on C-3 was reduced appropriately with the surgery. The postoperative radiographs obtained demonstrated good instrumentation placement. Three and a half years later the patient returned to the ED having expectorated the entire anterior cervical construct. A CT scan demonstrated the C-2 and C-3 vertebral bodies to be fused posteriorly with an anterior erosive defect within the vertebral bodies and the anterior fusion hardware at the $\mathrm{C} 2-3$ level no longer identified. The fiberoptic laryngoscopy demonstrated a $1 \times 1 \mathrm{~cm}$ area over the importation of the hypopharynx, above the glotic area. The Gastrografin swallowing test ruled out any esophageal tear or fistula and confirmed the presence of a large ulcer on the posterior wall of the oropharynx. To the best of the authors' knowledge, this is the first ever reported case of a tear in the posterior pharyngeal wall along with extrusion of the entire cervical construct after ACDF. This case demonstrates a rare but potentially serious complication of ACDF. Based on the available literature, each case requires separate and distinct treatment from the others.
\end{abstract}

https://thejns.org/doi/abs/10.3171/2016.10.SPINE16560

KEY WORDS anterior cervical discectomy and fusion; pharyngeal perforation; PEEK cage; cervical construct

$\Lambda$ NTERIOR cervical discectomy and fusion (ACDF) is a very common surgery performed globally for the treatment of radiculopathy and myelopathy due to degenerative disc diseases, spondylosis, and traumatic injuries. It is one of the most commonly performed spinal procedures in the US, with more than 100,000 surgeries performed yearly in the US alone with a successful outcome. $3,8,14,18,31,33,34,40,41$

Complications associated with ACDF such as postoperative dysphagia, postoperative hematoma, dural penetration, recurrent laryngeal nerve palsy, Horner's syndrome, esophageal perforation, and others have been reported in the literature. $6,8,9,23-25,28,36,39$ Although rare, these complications can be very perturbing and can sometimes lead to catastrophic outcomes. One of the most serious complications associated with ACDF surgery is the extrusion of the implanted instrumentation, with various consequences each time.

Esophageal tear is a very rare complication and pharyngeal tears are even more rare. To the best of our knowledge, only 1 case of pharyngeal perforation with extrusion of the graft along with the fixation pin has been reported in the literature. ${ }^{38}$ Here we present the very first case of extrusion of the entire cervical construct via a tear in the

ABBREVIATIONS ACDF = anterior cervical discectomy and fusion; $E D=$ emergency department; $P E E K=$ polyetheretherketone.

SUBMITTED May 13, 2016. ACCEPTED October 7, 2016.

INCLUDE WHEN CITING Published online February 3, 2017; DOI: 10.3171/2016.10.SPINE16560. 


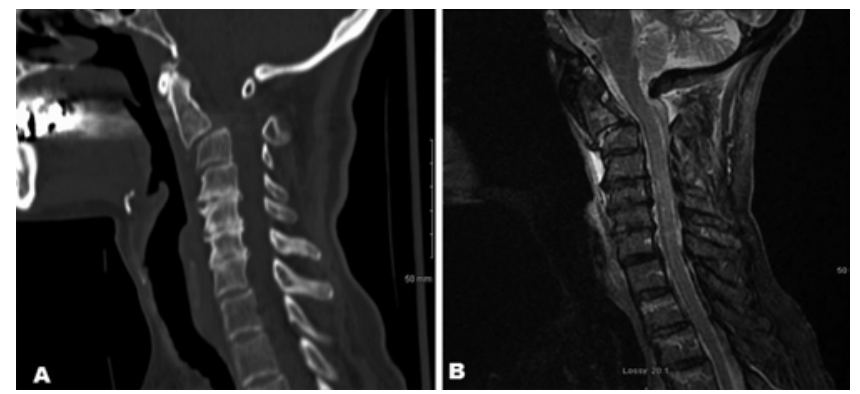

FIG. 1. Preoperative sagittal CT (A) and MR (B) images of the cervical spine showing severe anterior subluxation of $\mathrm{C}-2$ on $\mathrm{C}-3$ with bilateral $\mathrm{C}-2$ lamina fractures and multiple levels of degenerative disc disease. The cervical MR image also revealed a posterior interspinous ligament injury between the $\mathrm{C}-1$ and $\mathrm{C}-2$ levels.

posterior pharyngeal wall, along with a detailed review of all available literature on pharyngoesophageal perforations after ACDF surgeries.

\section{Case Report}

History and Examination

An 81-year-old woman presented to our emergency department (ED) with a complaint of significant cervical pain 5 days after a fall. The patient said she had landed and hit the back of her head due to a syncopal event. She exhibited no signs of neurological deficits. She denied having any paresis, radicular pain, or paresthesia. Her past medical and surgical history indicated that she had celiac disease and squamous cell carcinoma of the forehead region, for which she had undergone 3 surgical procedures to remove the carcinoma and also undergone plastic reconstruction of her nose and forehead region.

A CT scan of the cervical spine (Fig. 1A) showed severe anterior subluxation of C-2 on C-3 as a result of right-sided facet fracture, bilaterally perched facets, and multiple levels of degenerative disc disease throughout the cervical spine. A right vertebral artery occlusion with no spinal cord signal change was also noted radiographically. An MR image of the cervical spine (Fig. 1B) revealed significant C-2 subluxation; however, no cord signal change was noted at the level of the C-2 region. The posterior longitudinal ligament appeared to be intact, but there appeared to be disruption of the anterior longitudinal ligament. There was also a posterior interspinous ligament injury between the $\mathrm{C}-1$ and $\mathrm{C}-2$ levels.

\section{Operation and Postoperative Course}

The patient was examined by a neurosurgeon (other than the authors) at that time and underwent ACDF at the C2-3 level utilizing a polyetheretherketone (PEEK) cage, allograft, autograft, and a nontranslational plate with a locking apparatus and expanding screws. Variable screws $(4.0 \times 10 \mathrm{~mm})$ were used superiorly while fixed screws (4.0 $\times 12 \mathrm{~mm}$ ) were used inferiorly. The screws were secured properly on postoperative radiography, but the Grade II spondylolisthesis of C-2 on C-3 was not reduced appropriately with the surgery. The postoperative radiographs that were obtained demonstrated good instrumentation placement (Fig. 2A).

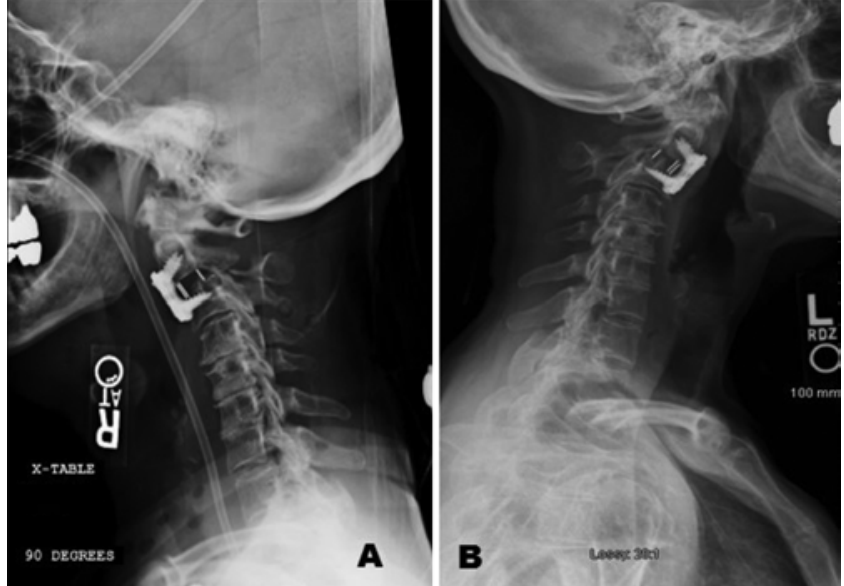

FIG. 2. Immediate postoperative lateral radiograph demonstrating good instrumentation placement $(\mathbf{A})$ and a 6 -month postoperative radiograph showing no osteophytes or fusion (B).

Postoperatively, she developed dysphagia. She was followed-up in clinic frequently with visits at 10 weeks, 14 weeks, 19 weeks, and 7 months after the surgery. Her cervical spine radiographs obtained at 10 weeks did not demonstrate bone fusion and the patient was placed back in her cervical thoracic orthotic. The review of 14- and 19-week radiographs showed stable fusion with some osteophytes at the C2-3 level. A radiograph at the 6-month follow-up evaluation showed no osteophytes or fusion (Fig. 2B). At her 7-month visit she had no complaints of any pain or discomfort, nor any difficulty in swallowing. She was able to swallow solid foods easily and was quite satisfied with her surgical outcome.

\section{Expulsion of Construct}

Three and a half years after the surgery the patient returned to the ED after having coughed up the entire anterior cervical construct (Fig. 3). During this visit she was evaluated by our neurosurgical team (the authors). According to her, she had been having bouts of coughing for the last couple of weeks with some foreign body sensation in the throat. The patient is a nonsmoker with no history of any smoking or illicit drug use. She denied any history of fever or chills. When coughing out the entire graft, construct, and plating system, both times she only had a small amount of blood-tinged sputum, but no frank blood. According to the patient, she felt much better after the expulsion of the apparatus and was finally able to eat. She denied any throat pain or difficulty with breathing, speech, or swallowing her saliva.

Her neurological and physical examination as well as the examination of the oropharynx were unremarkable with no signs of blood or defects in the posterior oropharynx visible at that time. A CT scan of the spine and soft tissue (Fig. 4A) demonstrated the C-2 and C-3 vertebral bodies to be fused posteriorly with an anterior erosive defect within the vertebral bodies and the anterior fusion hardware at the C2-3 level no longer identified. An ulcerative soft-tissue defect within the posterior pharyngeal wall was noticed. There was mild edema within the right posterior retropharyngeal space and the adjacent right 

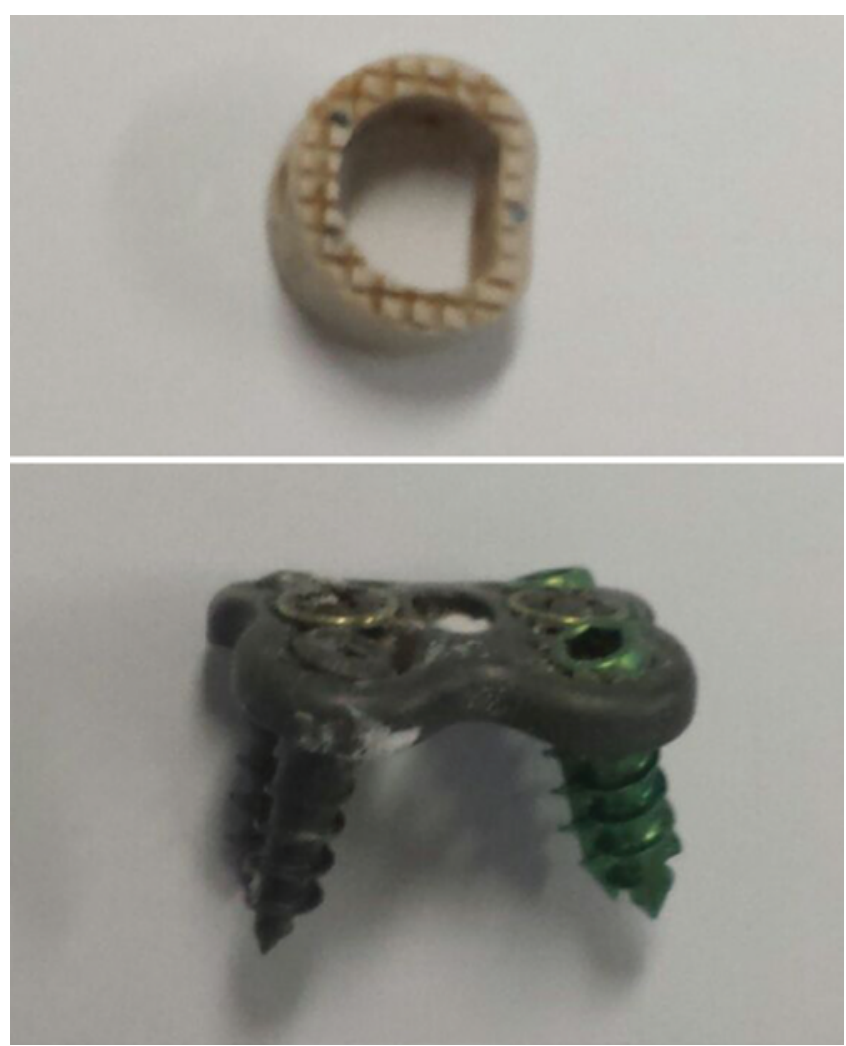

FIG. 3. Photographs of the entire anterior cervical construct (graft, plate, and 4 screws) that was coughed up. The green variable screws used are $4.0 \times 10 \mathrm{~mm}$ and the gray fixed screws are $4.0 \times 12 \mathrm{~mm}$. Figure is available in color online only.

vertebral artery appeared to be near completely occluded due to the surrounding right paravertebral and pharyngeal soft-tissue edema.

A fiberoptic laryngoscopy demonstrated a $1 \times 1 \mathrm{~cm}$ area/perforation in the hypopharynx, above the glotic area, with no evidence of abscess formation or inflammation in this area. Vocal cords showed slight edema and erythema, indicating mild laryngitis. The Gastrografin swallowing test ruled out any esophageal tear or fistula and confirmed a large ulcer on the posterior wall of the oral pharynx, along with a small Zenker's diverticulum (Fig. 5).

As per the ear, nose, and throat consult, the patient was not a surgical candidate for any type of pharyngeal repair and was allowed to heal by secondary intention. We recommended surgical fixation from an anterior and posterior approach, but the patient was against any further surgery. She was monitored in the hospital with a conservative approach for the next 3 weeks and put on a nothing-by-mouth diet along with antibiotic prophylaxis to prevent any abscess formation in the posterior pharyngeal wall during the healing process. Laparoscopic-assisted gastrostomy tube placement was performed to allow for the healing of the posterior pharyngeal wall for up to 4-6 weeks. She was discharged after 3 weeks, with flexion and extension films revealing a stable $\mathrm{C} 2-3$ junction (Fig. 6). She followed-up in our clinic about 2 weeks after the discharge. She was doing well at that time with no other neurosurgical issues. Her feeding tube had been removed
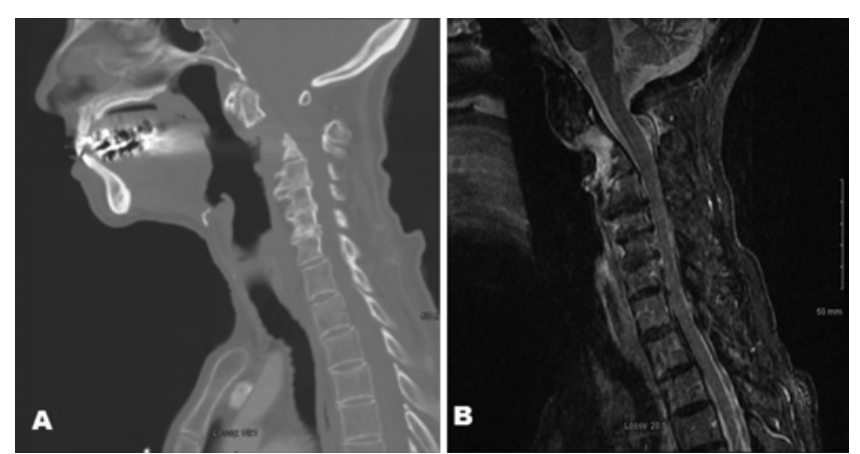

FIG. 4. A sagittal CT scan (A) and MR image (B) of the cervical spine demonstrating the $\mathrm{C}-2$ and $\mathrm{C}-3$ vertebral bodies to be fused posteriorly with an anterior erosive defect within the vertebral bodies, and the anterior fusion hardware at the $\mathrm{C} 2-3$ level can no longer be identified.

and she was swallowing without any difficulty. She followed up with occupational therapy and physical therapy/ physiotherapy for a few weeks and was eventually lost to follow-up.

\section{Discussion}

ACDF is a very commonly performed surgical procedure. Although rare, complications associated with this procedure can be very hazardous and can sometimes lead to catastrophic outcomes. Extrusion of the implanted instrumentation is one of the most serious complications among the possibilities. Esophageal tear is a very rare complication of ACDF and extrusion of instrumentation from an esophageal tear is even more rare. Some cases of coughing up screws or extrusion of screws into the gastrointestinal tract through esophageal perforations have previously been reported. . $^{8,11,13,44}$

Pharyngeal perforation after ACDF is extremely rare and only 1 case of pharyngeal perforation with extrusion of some cervical construct has been reported in the literature to date. ${ }^{38}$ Sharma et al. reported extrusion of a graft with its fixation pin 1 year after surgery in a 32-year-old woman with a C2-3 fracture following a motor vehicle accident. ${ }^{38}$ She already had the plating and screws removed 3 months following the surgery due to complaints of dysphagia and coughed up the remaining graft after developing dysphagia 1 year after the surgery through a pharyngeal tear. In this paper we present the first case of the extrusion
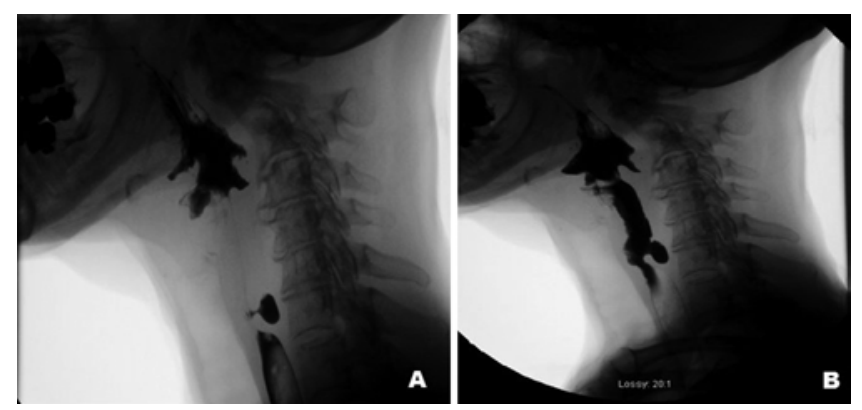

FIG. 5. Gastrografin esophagram ruling out any esophageal tear or fistula and demonstrating a large ulcer on the posterior oropharyngeal wall. A small Zenker's diverticulum can also be noted. 


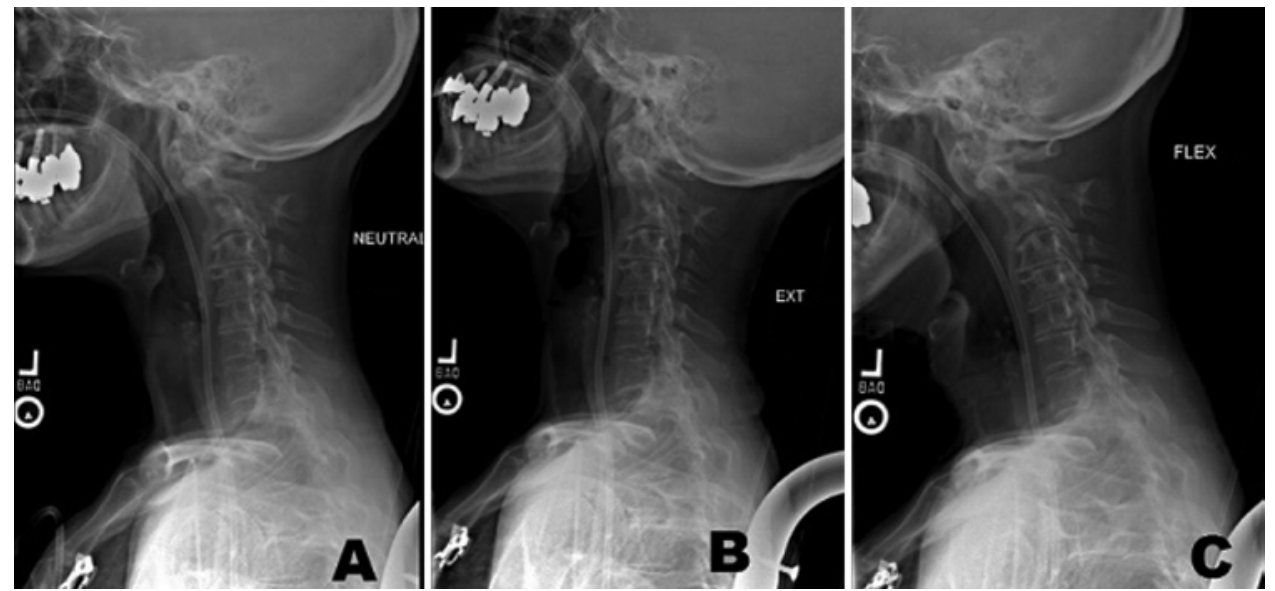

FIG. 6. Neutral (A), extension (B), and flexion (C) lateral radiographs obtained on Day 16 after extrusion demonstrating a stable C2-3 junction.

of the entire cervical construct, graft, and plate along with all 4 screws via a tear in the posterior pharyngeal wall.

Pharyngoesophageal perforations can ensue intraoperatively, perioperatively, or many years postoperatively, with a very low reported incidence rate of $0.25 \%-1.49 \% .17,27$ They may follow a benign course afterward or may lead to fatal complications; therefore, their early diagnosis and treatment are critical. Erosion of the hypopharynx or esophagus, with or without instrumentation failure, has been described as occurring up to many years $(n=13)$ postoperatively. ${ }^{20,23,33,43}$ When using the anterior cervical approach, acute injuries to oropharyngeal or laryngeal soft tissue can occur during the exposure of the atlantoaxial and subaxial regions while acute neuronal damage can ensue during bone grafting, manipulation of the spinal fracture/dislocation, and internal fixation, along with bone donor site problems. ${ }^{17,38}$ Nonetheless, delayed pharyngoesophageal perforation is considered to be due to a more complex mechanism. Different mechanisms suggested for pharyngoesophageal perforations include pressure sores caused by the metallic implant and its microtrauma effect. $8,11,13,17,21,38,44$ The chronic compression of the posterior wall of the pharyngoesophagus by the protuberant bone or the fixation device may lead to focal ischemia and necrosis, cellulitis, abscess formation, and eventually perforation. ${ }^{11,13,17,21,38,44}$ Delayed hardware failure with screw migration was found to be associated in as many as $35 \%$ of cases and is considered to be the most common cause of pharyngoesophageal injury following anterior cervical spine surgery. ${ }^{12}$

Cases of missing screws found in the gastrointestinal tract without any evidence of esophageal scarring have also been reported..$^{32}$ In such cases, the esophageal perforations have probably healed without any clinically significant symptoms. Therefore, the incidence of esophageal perforation due to instrumentation extrusion is considered to be underreported, and this appears to explain the low incidence rate $(<1.5 \%)$ reported in the literature. . $^{60,29}$

Although the suggested mechanisms for both pharyngeal and esophageal perforation are the same, pharyngeal perforations are very rare as compared with the number of esophageal perforations reported in the literature. We attribute this to the comparative frequencies of fixations performed at different levels rather than anything else. With an extensive review of the literature we found that the most common levels of fixation reported to be affected were C4-7 levels, which could be attributed to the increased frequency of fixation at this level. ${ }^{29}$ Hence, pharyngeal perforation with involvement of the $\mathrm{C} 2-3$ level is very rare, with this case being only the second case to be reported in the literature to the best of our knowledge, and the very first case of extrusion of the entire cervical construct through a posterior pharyngeal wall tear.

In this particular case, when investigating the past records from her initial visit 3.5 years earlier, our team is of the opinion that the patient should have initially undergone an anterior and posterior fusion for treatment. We believe that the patient might have benefited much if an anterior and posterior approach had been adopted by the treating surgeon at the time. Although the use of anterior plating has remained controversial, it is a common practice among spine surgeons. ${ }^{4,15,19,37}$ After the expectoration of the entire anterior cervical construct, the patient was recommended to undergo surgical fixation from an anterior and posterior approach by our team, but she opted against any further surgical procedure.

Apart from various contributing factors that vary from case to case, an in-depth examination of all the reported cases, including our case, indicates that the initial suboptimal positioning of the screws can be considered as the main predisposing factor for extrusion of the screws or construct. ${ }^{8,11,13,44}$ The avoidance of the false belief that locking, expanding screws cannot be extruded could minimize the incidence of extrusion. In the literature we found extrusion of both nonlocking, conventional screws and locking, expanding screws to have been reported repeatedly. $5,6,11,13,44$ However, we were unable to establish any significant relation between extrusion and size of the screws used for fixation. In our case, along with osteoporosis, the reason for the extrusion of screws and construct could be due to the nonfusion caused by suboptimal placement of the screws and the PEEK cage. On her initial presentation with cervical injury, our patient had a right vertebral artery injury. We speculate that in our case, the $1.2 \times 0.7-\mathrm{cm}$ 
anterior erosive defect observed within the C-2 and C-3 vertebral bodies in the location of prior hardware, leading to this patient's hardware failure, was due to the lack of blood supply to the vertebral bodies at the C2-3 level resulting in osteonecrosis and osteomyelitis (Fig. 4).

Characteristically it was also noted that, in short fusion cases, the superior screws were the ones that were extruded, while in long, multilevel fusions the lower screws were commonly pulled out. ${ }^{8,11,13,44}$ In contrast, Lee et al. presented a case of bi-level fusion in which the superior screws failed. ${ }^{21}$

When there is an accompanying posterior ligamentous instability, it can lead to disarticulation of the bone graft with repeated angulation or displacement. ${ }^{38}$ Although screw and plate extrusions are rare, graft extrusions are even more rare. Apart from our case, only Sharma et al. have reported the extrusion of a graft with its fixation device and emphasized that the failure of the fixation device does not necessarily mean the failure of fusion..$^{38}$ In the presented case we contemplate that the reasons for nonfusion of the graft are the improper arthrodesis of endplates, improper placement of the graft, osteoporosis, vertebral artery injury resulting in osteonecrosis, and possibly an underlying infection (osteomyelitis) that caused erosion of the bone, thereby loosening the construct.

Pharyngoesophageal perforation with the extrusion of screws or any part of the cervical construct can lead to devastating consequences such as death from septicemia, mediastinitis, aspiration of extruded instrumentation into the lungs, pneumonia, or meningitis. ${ }^{11,13,17,21,38,44}$ In the previously reported cases of esophageal perforations no catastrophic complications were reported and attributed; this could be due to the chronic, slow-evolving erosion mechanism behind esophageal perforations. ${ }^{8,11,13,44}$ Because these perforations may either follow a benign course or lead to any of the previously mentioned fatal complications, their early diagnosis and treatment are critical.

Due to infrequent reporting with a low documented incidence rate, the presentation, appropriate evaluation, and management of delayed pharyngoesophageal perforation from ACDF is not well understood. Symptomatically delayed pharyngoesophageal perforation should be considered whenever a patient who has undergone ACDF, even several years prior, presents with complaints of dysphagia, unexplained fever, hoarseness, chronic coughing with foreign body sensation, pain, or odynophagia. ${ }^{6,8,11,13,17,21,22,29,35}$, ${ }^{38,44}$ Dysphagia was found to be the most common symptom reported in the literature. Neck abscess and aspiration pneumonia, due to traveling of oropharyngeal secretions through the perforation, are also the most commonly reported presenting symptoms and warrant further investigation for a potential pharyngoesophageal perforation in a patient with a history of ACDF surgery. ${ }^{29}$ Although nonspecific, occasionally one of the presenting symptoms in such patients might be a midthoracic pain radiating to the shoulders; in most of these patients this symptom may just be the result of their cervical degenerative disease. ${ }^{6}$ In cases of perioperative perforation, aspiration or drainage of food, saliva, or air from the neck incision site can be observed. ${ }^{35}$ Our patient presented with symptoms of dysphagia and bouts of coughing for the last couple of weeks with some foreign body sensation in the throat prior to the extrusion of instrumentation.

With regard to the diagnosis of this potentially lethal complication, the presence of any dysphagia or sore throat, with or without chronic cough or hoarseness, or the evidence of loosening of the implanted screws more than 5 $\mathrm{mm}$ on radiographic images, should alert the clinician and lead to an early diagnosis. ${ }^{6,22}$ Imaging modalities for such a complication should include a contrast esophagram, which is known to demonstrate $75 \%-100 \%$ accuracy in diagnosing esophageal perforation. ${ }^{26,27,42}$ Esophagoscopy, which has an accuracy rate of $63.6 \%$ for diagnosing perforations, should be performed to directly inspect the posterior pharynx and esophagus for exposed intraluminal hardware. ${ }^{17,27}$ Computed tomography is useful for indicating extraesophageal air or abscess while plain radiographs of the spine are effective at demonstrating pneumomediastinum or air in the retropharyngeal and prevertebral spaces. ${ }^{6,16,42}$ MRI can be used to evaluate cervical alignment and the status of spinal fixation. ${ }^{17}$

In our case, apart from the CT and MRI, we performed a fiberoptic laryngoscopy to directly inspect the posterior pharynx, and a Gastrografin swallowing test was performed to rule out any esophageal tear or fistula.

The treatment options for esophageal perforation from anterior cervical spine hardware include managing it conservatively, by primary closure or by complex reconstruction. ${ }^{7,12,35}$ Successful conservative management of small perforations includes drainage without repair, use of broad-spectrum intravenous antibiotics, a nasogastric tube, and extraoral nutrition. . $, 2,12,16,26,42,43$ Conservative management is a reasonable option in patients with uncomplicated esophageal injuries and contained leaks, with a survival rate of $80 \%{ }^{1,2,12,16,26,42}$ In our case we pursued a conservative approach. A laparoscopic-assisted gastrostomy tube placement was performed before discharge near the end of the 3rd week to allow for the healing of the posterior pharyngeal wall for up to 6 weeks.

Most cases of esophageal perforation due to instrumentation erosion are unlikely to resolve with conservative management alone and require surgical closure.? A surgical exploration is necessary when neck abscess, recurrent aspiration pneumonia, or clinical signs of sepsis develop. ${ }^{29}$ Larger defects may require vascularized flaps such as a submental island flap, pectoralis major myogenous flap, sternocleidomastoid muscle, or a microvascular free flap. ${ }^{7,10,12,20,29,30}$ For a successful repair it is essential that the displaced instrumentation should be removed as completely as possible because if the instrumentation is left intact the perforation may recur. ${ }^{12,20,29}$

In cases with initial suboptimal implantation of the instrumentation the importance of close follow-up cannot be overstressed. In our opinion, the manifestation of any of the commonly documented presenting symptoms over the years, especially dysphagia, should alert clinicians and warrant further investigation.

\section{Conclusions}

This case demonstrates a rare, but potentially serious and life-threatening complication of ACDF. The pre- 
sented case is different from all other cases because of the extrusion of the entire cervical construct along with the implanted graft. Based on the available literature, each case requires separate and distinct treatment from the others. This case demonstrates that patients with multiple risk factors for hardware failure, including poor bone quality and diminished vascular supply to the fused elements, should be followed clinically longer than other postoperative patients due to the potential for significant delayed complications. Our patient did well clinically and required no further intervention, showing stability on flexion and extension radiographs, but each case is unique for such a rare complication.

\section{References}

1. Attar S, Hankins JR, Suter CM, Coughlin TR, Sequeira A, McLaughlin JS: Esophageal perforation: a therapeutic challenge. Ann Thorac Surg 50:45-51, 1990

2. Barlow CW, Schein M: Primary sternocleidomastoid muscle flap in emergency reconstruction of traumatic oesophageal defect. Case report. Eur J Surg 157:419-420, 1991

3. Bohlman HH, Emery SE, Goodfellow DB, Jones PK: Robinson anterior cervical discectomy and arthrodesis for cervical radiculopathy. Long-term follow-up of one hundred and twenty-two patients. J Bone Joint Surg Am 75:1298-1307, 1993

4. Brown JA, Havel P, Ebraheim N, Greenblatt SH, Jackson WT: Cervical stabilization by plate and bone fusion. Spine (Phila Pa 1976) 13:236-240, 1988

5. Chataigner H, Gangloff S, Onimus M: Elimination spontanee de visd'osteosynthese cervicale anterieure par les voies naturelles. Rev Chir Orthop Repar Appar Mot 83:78-82, 1997

6. Cloward RB: Complications of anterior cervical disc operation and their treatment. Surgery 69:175-182, 1971

7. Davison SP, Yoder BE, Boehmler JH IV: Repairing esophageal perforations with a transverse cervical musculofascial flap. Ann Plast Surg 57:164-168, 2006

8. Fountas KN, Kapsalaki EZ, Machinis T, Robinson JS: Extrusion of a screw into the gastrointestinal tract after anterior cervical spine plating. J Spinal Disord Tech 19:199-203, 2006

9. Fountas KN, Kapsalaki EZ, Nikolakakos LG, Smisson HF, Johnston KW, Grigorian AA, et al: Anterior cervical discectomy and fusion associated complications. Spine (Phila Pa 1976) 32:2310-2317, 2007

10. Friedman M, Toriumi DM, Strorigl T, Chilis T, Skolnik E: The sternocleidomastoid myoperiosteal flap for esophagopharyngeal reconstruction and fistula repair: clinical and experimental study. Laryngoscope 98:1084-1091, 1988

11. Fujibayashi S, Shikata J, Kamiya N, Tanaka C: Missing anterior cervical plate and screws: a case report. Spine (Phila Pa 1976) 25:2258-2261, 2000

12. Gaudinez RF, English GM, Gebhard JS, Brugman JL, Donaldson DH, Brown CW: Esophageal perforations after anterior cervical surgery. J Spinal Disord 13:77-84, 2000

13. Geyer TE, Foy MA: Oral extrusion of a screw after anterior cervical spine plating. Spine (Phila Pa 1976) 26:1814-1816, 2001

14. Gore DR, Sepic SB: Anterior cervical fusion for degenerated or protruded discs. A review of 146 patients. Spine (Phila Pa 1976) 9:667-671, 1984

15. Grob D, Peyer JV, Dvorak J: The use of plate fixation in anterior surgery of the degenerative cervical spine: a comparative prospective clinical study. Eur Spine J 10:408-413, 2001

16. Hinojar AG, Díaz Díaz MA, Pun YW, Hinojar AA: Manage- ment of hypopharyngeal and cervical oesophageal perforations. Auris Nasus Larynx 30:175-182, 2003

17. Jamjoom ZAB: Pharyngo-cutaneous fistula following anterior cervical fusion. Br J Neurosurg 11:69-74, 1997

18. Jenis LG, An HS, Simpson JM: A prospective comparison of the standard and reverse Robinson cervical grafting techniques: radiographic and clinical analyses. J Spinal Disord 13:369-373, 2000

19. Kaiser MG, Haid RW Jr, Subach BR, Barnes B, Rodts GE Jr: Anterior cervical plating enhances arthrodesis after discectomy and fusion with cortical allograft. Neurosurgery 50:229-238, 2002

20. Kau RL, Kim N, Hinni ML, Patel NP: Repair of esophageal perforation due to anterior cervical spine instrumentation. Laryngoscope 120:739-742, 2010

21. Lee JS, Kang DH, Hwang SH, Han JW: Oral extrusion of screw after anterior cervical interbody fusion. J Korean Neurosurg Soc 44:259-261, 2008

22. Lowery GL, McDonough RF: The significance of hardware failure in anterior cervical plate fixation. Patients with 2- to 7-year follow-up. Spine (Phila Pa 1976) 23:181-187, 1998

23. Lu DC, Theodore P, Korn WM, Chou D: Esophageal erosion 9 years after anterior cervical plate implantation. Surg Neurol 69:310-313, 2008

24. Lunsford LD, Bissonette DJ, Jannetta PJ, Sheptak PE, Zorub DS: Anterior surgery for cervical disc disease. Part 1: Treatment of lateral cervical disc herniation in 253 cases. J Neurosurg 53:1-11, 1980

25. Martino V, Nina P, Franco A, Di Benedetto A, Chiappetta F, Schisano G: Cervical myelopathy caused by median disc herniation: analysis of the complications following anterior discectomy with and without Fusion Report of 90 cases. J Neurosurg Sci 41:153-158, 1997

26. Michel L, Grillo HC, Malt RA: Operative and nonoperative management of esophageal perforations. Ann Surg 194:5763,1981

27. Newhouse KE, Lindsey RW, Clark CR, Lieponis J, Murphy MJ: Esophageal perforation following anterior cervical spine surgery. Spine (Phila Pa 1976) 14:1051-1053, 1989

28. Parthiban JK, Singhania BK, Ramani PS: A radiological evaluation of allografts (ethylene oxide sterilized cadaver bone) and autografts in anterior cervical fusion. Neurol India 50:17-22, 2002

29. Phommachanh V, Patil YJ, McCaffrey TV, Vale F, Freeman TB, Padhya TA: Otolaryngologic management of delayed pharyngoesophageal perforation following anterior cervical spine surgery. Laryngoscope 120:930-936, 2010

30. Pichler W, Maier A, Rappl T, Clement HG, Grechenig W: Delayed hypopharyngeal and esophageal perforation after anterior spinal fusion: primary repair reinforced by pedicled pectoralis major flap. Spine (Phila Pa 1976) 31:E268-E270, 2006

31. Pokras R: Surgical and nonsurgical procedures in short-stay hospitals. Vital Health Stat 13 70:1-41, 1983

32. Pompili A, Canitano S, Caroli F, Caterino M, Crecco M, Raus L, et al: Asymptomatic esophageal perforation caused by late screw migration after anterior cervical plating: report of a case and review of relevant literature. Spine (Phila Pa 1976) 27:E499-E502, 2002

33. Riley LH Jr, Robinson RA, Johnson KA, Walker AE: The results of anterior interbody fusion of the cervical spine. Review of ninety-three consecutive cases. J Neurosurg 30:127-133, 1969

34. Robinson R, Walker A, Ferlic D, Wieckling OK: The results of anterior interbody fusion of the cervical spine. J Bone Joint Surg Am 44:1569-1587, 1962

35. Sahjpaul RL: Esophageal perforation from anterior cervical screw migration. Surg Neurol 68:205-210, 2007

36. Salam MA, Cable HR: Acquired pharyngeal diverticulum 
following anterior cervical fusion operation. Br J Clin Pract 48:109-110, 1994

37. Samartzis D, Shen FH, Lyon C, Phillips M, Goldberg EJ, An HS: Does rigid instrumentation increase the fusion rate in one-level anterior cervical discectomy and fusion? Spine $\mathbf{J}$ 4:636-643, 2004

38. Sharma RR, Sethu AU, Lad SD, Turel KE, Pawar SJ: Pharyngeal perforation and spontaneous extrusion of the cervical graft with its fixation device: a late complication of C2-C3 fusion via anterior approach. J Clin Neurosci 8:464-468, 2001

39. Tew JM Jr, Mayfield FH: Complications of surgery of the anterior cervical spine. Clin Neurosurg 23:424-434, 1976

40. White AA III, Southwick WO, DePonte RJ, Gainor JW, Hardy R: Relief of pain by anterior cervical-spine fusion for spondylosis. A report of sixty-five patients. J Bone Joint Surg Am 55:525-534, 1973

41. Williams JL, Allen MB Jr, Harkess JW: Late results of cervical discectomy and interbody fusion: some factors influencing the results. J Bone Joint Surg Am 50:277-286, 1968

42. Witwer BP, Resnick DK: Delayed esophageal injury without instrumentation failure: complication of anterior cervical instrumentation. J Spinal Disord Tech 16:519-523, 2003

43. Woolley SL, Smith DR: Pharyngeal perforation: a late complication of cervical spine surgery. J Laryngol Otol 119:913-916, 2005

44. Yee GK, Terry AF: Esophageal penetration by an anterior cervical fixation device. A case report. Spine (Phila Pa 1976) 18:522-527, 1993

\section{Disclosures}

The authors report no conflict of interest concerning the materials or methods used in this study or the findings specified in this paper.

\section{Author Contributions}

Conception and design: Quadri, Sweiss. Drafting the article: Quadri, Capua, Ramakrishnan, Sweiss, Cabanne, Noel. Critically revising the article: Capua, Sweiss, Cabanne, Noel. Reviewed submitted version of manuscript: Quadri, Capua, Sweiss, Fiani. Study supervision: Siddiqi.

\section{Supplemental Information}

Previous Presentations

The abstract for this case was presented at the 83rd Annual Scientific Meeting of the AANS in Washington, DC, May 2-6, 2015.

\section{Correspondence}

Syed A. Quadri, Desert Regional Medical Center, 1180 N Indian Canyon Dr., Ste. 214 W, Palm Springs, CA 92262. email: dr.saqader@gmail.com. 